\title{
Shaping development through mechanical strain: the transcriptional basis of diet-induced phenotypic plasticity in a cichlid fish
}

\author{
HELEN M. GUNTER,${ }^{*} \dagger$ SHAOHUA FAN,$*$ FAN XIONG,$*$ PAOLO FRANCHINI, $*$ \\ CARMELO FRUCIANO* and AXEL MEYER* \\ *Lehrstuhl für Zoologie und Evolutionsbiologie, Department of Biology, University of Konstanz, Universitätstrasse 10, \\ 78457 Konstanz, Germany, $\dagger$ Zukunftskolleg, University of Konstanz, Universitätstrasse 10, 78457 Konstanz, Germany
}

\begin{abstract}
Adaptive phenotypic plasticity, the ability of an organism to change its phenotype to match local environments, is increasingly recognized for its contribution to evolution. However, few empirical studies have explored the molecular basis of plastic traits. The East African cichlid fish Astatoreochromis alluaudi displays adaptive phenotypic plasticity in its pharyngeal jaw apparatus, a structure that is widely seen as an evolutionary key innovation that has contributed to the remarkable diversity of cichlid fishes. It has previously been shown that in response to different diets, the pharyngeal jaws change their size, shape and dentition: hard diets induce an adaptive robust molariform tooth phenotype with short jaws and strong internal bone structures, while soft diets induce a gracile papilliform tooth phenotype with elongated jaws and slender internal bone structures. To gain insight into the molecular underpinnings of these adaptations and enable future investigations of the role that phenotypic plasticity plays during the formation of adaptive radiations, the transcriptomes of the two divergent jaw phenotypes were examined. Our study identified a total of 187 genes whose expression differs in response to hard and soft diets, including immediate early genes, extracellular matrix genes and inflammatory factors. Transcriptome results are interpreted in light of expression of candidate genes markers for tooth size and shape, bone cells and mechanically sensitive pathways. This study opens up new avenues of research at new levels of biological organization into the roles of phenotypic plasticity during speciation and radiation of cichlid fishes.
\end{abstract}

Keywords: acellular bone, Astatorochromis alluaudi, cichlid, molluscivory, phenotypic plasticity, pharyngeal jaw, RNA-seq

\section{Introduction}

Recent years have seen a renewed interest in hypotheses that were originally put forward by Waddington and Schmalhausen, namely that phenotypes are not determined solely by the genotype, but rather through interactions between the genotype and internal and external environmental influences (Schmalhausen 1949; Waddington 1953; Gilbert 2001, 2012; Bosch \& McFall-Ngai

Correspondence: Axel Meyer, Fax: +49 (0) 753188 3018;

E mail: axel.meyer@uni konstanz.de
2011). Through providing a better match to local environments than purely genetically encoded phenotypes, environmentally induced phenotypes can offer a selective advantage, providing fuel for evolution (WestEberhard 2003, 2005; Pigliucci 2007; Jablonka \& Raz 2009). Developmental plasticity is known to be the basis of divergent adult phenotypes in well-known adaptive radiations such as spadefoot toads (Gomez-Mestre \& Buchholz 2006), sticklebacks (Day et al. 1994; Day \& McPhail 1996; Wund et al. 2008) and Anolis lizards (Losos et al. 2000; Kolbe \& Losos 2005), potentially contributing to their speciation. Even phenotypic 
plasticity itself is a trait that appears to be subject to natural selection (Crispo 2007; Schwander \& Leimar 2011). Divergent traits that arise initially through phenotypic plasticity can subsequently be encoded by the genome through the process of genetic assimilation and enriched through natural selection (Schmalhausen 1949; Waddington 1953; West-Eberhard 2003; Schwander \& Leimar 2011). Current neo-Darwinian paradigms do not account for the role of phenotypic plasticity in speciation, maintaining an exclusive focus on heritable variability (Pigliucci 2007). However, as natural selection acts upon phenotypes rather than on genotypes, determining whether genetic assimilation contributes to speciation remains an important unanswered question of evolutionary biology one that potentially allows us to bridge genotypic and phenotypic aspects of evolution. It has now become possible to address an important aspect of phenotypic plasticity that remained largely unknown until now: its molecular basis (Aubin-Horth \& Renn 2009; Beldade et al. 2011). The understanding of this is also the key to testing the importance of genetic assimilation, as regulatory evolution of plasticity-related genes has the potential to mediate their environmental responsiveness and thus, the degree of phenotypic plasticity displayed by different lineages.

Cichlid fishes of the East African rift lakes have formed famously diverse adaptive radiations that arose by extremely rapid speciation. They display an astonishing array of morphological and behavioural traits in spite of their young evolutionary age in the case of Lake Victoria, its 500 species are $<100000$ years old and are characterized by only minute genetic differences (Meyer et al. 1990; Salzburger et al. 2005; KisheMachumu et al. 2008; Elmer et al. 2009). Phenotypic plasticity may have contributed to cichlid diversification as it is known to generate morphological variants that responded to altered feeding ecologies, facilitating access to new trophic niches or to a more efficient exploitation (Meyer 1987, 1993; Wimberger 1994; Stauffer \& Gray 2004). To date, the best-studied cichlid example of phenotypic plasticity involves hypertrophy of the lower pharyngeal jaw (LPJ) of Astatoreochromis alluaudi in response to a mechanically robust diet, making it an excellent model system in which to characterize the molecular basis of phenotypic plasticity (Fig. 1a) (Greenwood 1959, 1965; Hoogerhoud 1986b; Huysseune et al. 1994; Huysseune 1995; Smits et al. 1996b).

Cichlids posses a pharyngeal jaw apparatus (PJA) with unique morphological features that facilitate the exploitation of a myriad of trophic niches including the crushing of very hard food items such as particular lineages of snails (Fig. 1b). Comprised of the upper and lower pharyngeal jaws and associated muscle attachments, the cichlid PJA represents a second functional set of jaws that take over the role of mastication from the oral jaws. This has lead to a functional decoupling between the oral and pharyngeal jaws, expanding their 'degrees of freedom' to evolve considerably more diverse modes of food acquisition than virtually all other families of fishes (Liem 1973). As a result, the cichlid PJA has been interpreted as an evolutionary key innovation that may, at least in part, be responsible for the extraordinary evolutionary success of cichlids (Liem 1973; Stiassny \& Jensen 1987).

Astatoreochromis alluaudi is a relatively widely distributed cichlid species, inhabiting Lake Victoria, as well as its surrounding satellite lakes (Greenwood 1959, 1965). Two morphs have been identified for this species: a molariform morph with a robust LPJ (Liem 1973; Stiassny \& Jensen 1987), studded with large, molar-like teeth; and a papilliform morph with a more gracile LPJ, bearing small, delicate teeth (Hoogerhoud 1986b; Huysseune et al. 1994; Huysseune 1995). Molariform populations inhabit Lake Victoria, feeding primarily on hard-shelled snails, which are cracked using their robust pharyngeal jaws (Greenwood 1965; Witte 1981), while individuals from satellite lake populations are more often papilliform, ingesting a range of softer food items, with a preference for insects (Slootweg et al. 1994). Molariform and papilliform jaws show a higher degree of efficiency in processing hard and soft diets, respectively (Meyer 1989); thus, each phenotype represents a trade-off and is adaptive depending on the ecological niche in which it is expressed. So striking are the differences in LPJ morphology that these populations were initially classified into two separate subspecies (Greenwood 1959). Later, it was recognized that these differences are caused by phenotypic plasticity when Greenwood examined an adult aquarium-bred individual, descended from a wild-caught Lake Victoria (molariform) stock, he found that its LPJ differed markedly from the source population, more strongly resembling satellite lake (papilliform) specimens (Greenwood 1965). Several further studies have shown that for A. alluaudi as well as other species of cichlid fish, the LPJ morphology is affected by diet, where a hard diet induces a molariform LPJ and a soft diet retains an ontogenetically and phylogenetically earlier papilliform LPJ (Greenwood 1965; Hoogerhoud 1986b; Smits 1996; Muschick et al. 2011). Detailed morphological analyses of A. alluaudi's LPJ suggest that mechanical strain induced by cracking hard-shelled snails is instrumental in shaping the molariform morphology (Huysseune et al. 1994; Huysseune 1995); however, to date, this phenotypic response had not been examined at the molecular level.

Mechanical forces are inherently linked to skeletal development, whereby the shape, size and density of bones typically reflect the forces applied to them an 

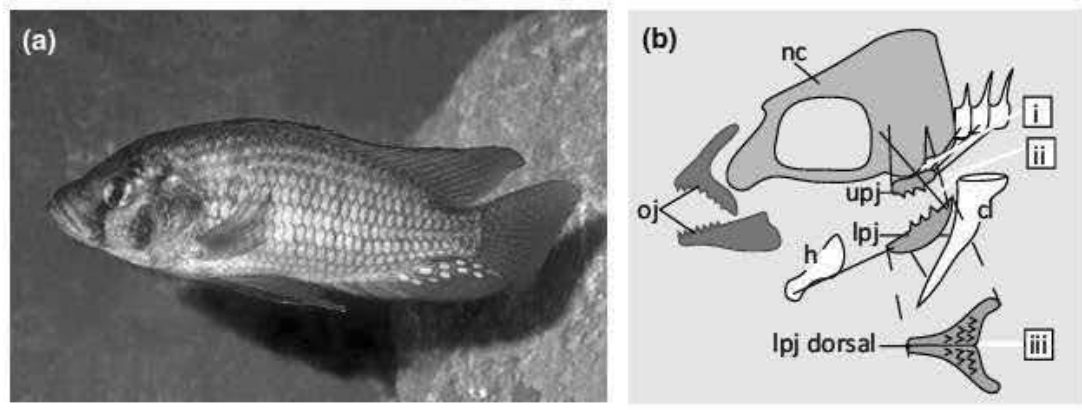

Fig. 1 (a) Astatoreochromis alluaudi, an East African cichlid includes two naturally occurring morphs that differ in their trophic ecolo gies and morphology of their pharyngeal jaws. Photograph provided by Erwin Schraml. (b) The pharyngeal jaw apparatus of cichlid fishes displays three morphological features that make it well suited to crushing: (i) the upper jaw articulates with the neurocranium, (ii) the lower pharyngeal jaw (LPJ) is suspended in a muscular sling, connecting the neurocranium to the posterior muscular arms of the lower jaw and (iii) the two 5th gill arches are sutured to form a single unit, the LPJ. (cl) Cleithrum, (h) hyoid, (lpj) lower pharyn geal jaw, (nc) neurocranium, (oj) oral jaw, (upj) upper pharyngeal jaw are indicated. Image modified from (Mabuchi et al. 2007).

idea originally described by Julius Wolff (Chamay \& Tschantz 1972). Since then, considerable insight has been gained on the cellular and molecular basis of bone growth and modification, through both in vitro and in vivo investigations on mammalian bones (Liedert et al. 2006; Thompson et al. 2012). Lacking osteocytes (living cells embedded in bones), which are assumed to be units of strain detection, the acellular bones of derived teleosts (such as cichlids) display fundamental differences to those of mammalian cellular bones (Moss 1962). Modelling and remodelling in derived teleosts largely relies on mononucleated osteoclasts (boneresorbing cells), which differ considerably from the massive multinucleated osteoclasts of mammals. Still, common pathways regulate osteoclasts both in teleosts and mammals (Witten \& Huysseune 2009). In mammals, bone remodelling is achieved through the tightly coupled activity of osteoclasts and osteoblasts (bonesecreting cells) (Lemaire et al. 2004). This response is coordinated by osteocytes, which sense localized shear stresses in the bone, launching a transcriptional response that leads to the proliferation and differentiation of both osteoblasts and osteoclasts (Klein-Nulend et al. 2005; Bonewald 2011). Previous investigations on mammalian bone provide sets of candidate genes of known function that can be investigated comparatively in fish.

In this study, the molecular basis of diet-induced plasticity in A.alluaudi's LPJ was examined through using combined morphological and transcriptional investigations. Several pathways underlying the molariform phenotype were identified, many of which are known to respond to mechanical strain in the bones and teeth of mammals. Furthermore, we identified the upregulation of several genes that promote osteoblast proliferation and differentiation, matrix remodelling and calcium signalling, and the downregulation of inflammatory markers, which together are likely to shape the molariform morphology. Our study sheds light on questions concerning the molecular basis of phenotypic plasticity, opening the door for future studies of genetic assimilation that investigate its potential contribution to the adaptive radiation of cichlid fishes. Moreover, we add to previous molecular studies of phenotypic plasticity in cichlids (Burmeister et al. 2005; Aubin-Horth et al. 2007; Renn et al. 2008; Huffman et al. 2012).

\section{Material and methods}

\section{Specimens used in this study}

We conducted a controlled diet experiment on an inbred strain of Astatoreochromis alluaudi, obtained from Frans Witte in 2008, which was originally collected from the Mwanza Gulf of Lake Victoria in 1984. A single brood, 60 individuals, was raised on Artemia salina nauplii and TetraMin flake food until they reached $30 \mathrm{~mm}$ standard length (SI). This brood was then divided into two groups in substrate-free $100-\mathrm{L}$ aquaria for 18 months on one of two experimental diets: the hard diet (HD) group was fed hard-shelled gastropod molluscs (Melanoides sp.), and the soft diet (SD) group was fed equivalent amounts of frozen, pulverized Melanoides sp. snails (similar to methods described in Muschick et al. (2011)). The diets were supplemented with TetraMin flakes. At the end of the experimental period, fish were sexually mature and many exceeded $80 \mathrm{~mm}$ SL, a size at which overt differences in jaw morphology were expected (Hoogerhoud 1986a; Huysseune et al. 1994; Smits et al. 1996b). Fish were killed according to local ethics regulations, and LPJs were dissected up to $30 \mathrm{~min}$ after feeding, so as to capture the patterns of transcription induced by a robust diet on both 
immediate and long-term levels. LPJs were stored in RNAlater (Qiagen) according to manufacturer's instructions for subsequent use in morphometric and transcriptional analyses.

\section{Morphometric analyses}

While submerged in RNAlater, LPJs were cleaned of surrounding connective tissues and photographed in both dorsal and ventral orientations under a dissection microscope. LPJs were then weighed to an accuracy of $0.0001 \mathrm{~g}$ after RNAlater was blotted with a Kimwipe. To test for differences in size between treatments and to facilitate comparison to previous studies, linear measurements were obtained either digitally from photographed specimens, or with dial callipers in the case of jaw depth (Fig. 2a d). The area and centroid size of each pharyngeal jaw were estimated from the $x \mathrm{y}$ coordinates of landmarks and semilandmarks that were also used in the geometric morphometric analysis (Fig. 2d; see below) by using Matlab (version R2010a; Mathworks Inc.). Additionally, pharyngeal jaw volume was estimated by multiplying LPJ area by LPJ depth. Tooth size was estimated by adding together measurements of

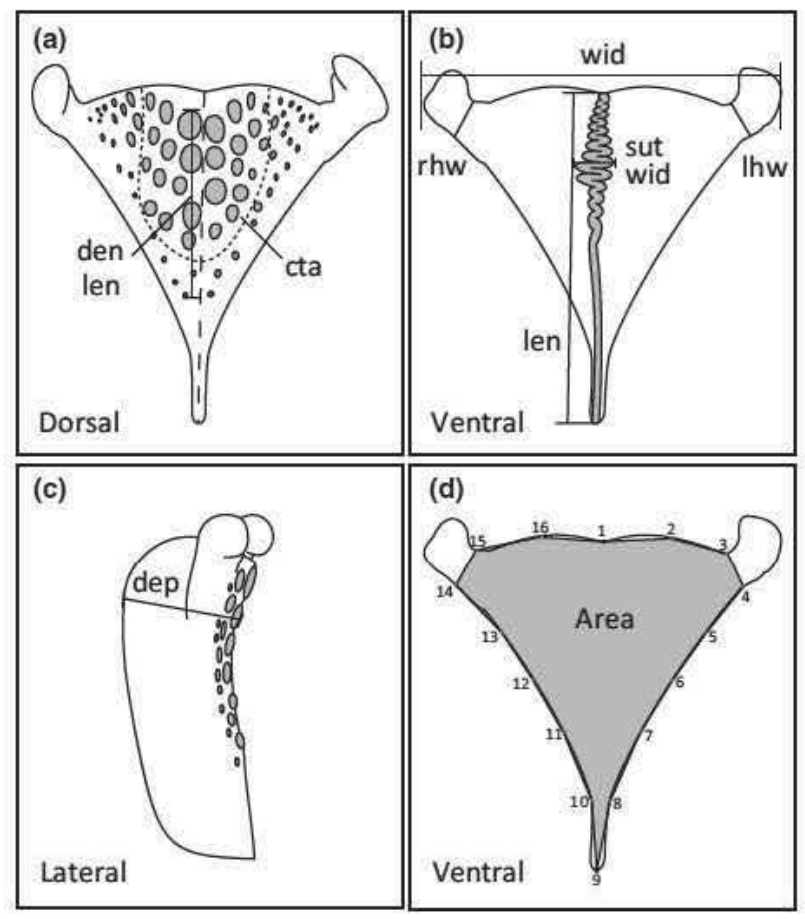

Fig. 2 Measurements made for traditional and geometric morphometric analyses. Traditional morphometric measure ments included (a) central toothed area (cta), dentigerous length (den len), (b) length (len), width (w), left horn width (lhw), right horn width (rhw), suture width (sut wid) and (c) depth (d). (f) Landmarks and semilandmarks used for the geometric morphometric analyses, and for calculation of area. tooth length and width, which were obtained from the photographs. Each of these measurements was then log-transformed and subjected to an analysis of covariance (ANCOVA) in STATISTICA (StatSoft, Inc.), using SL as a covariate (to account for allometric variation) and sex and treatment as categorical variables. A principal component analysis (PCA) was also carried out in NTSYSpc (Rohlf 2007a) on the correlation matrix of the log-transformed measurements, producing plots of the scores on the first two PC axes to explore overall patterns of variation in the data set.

Using digital images of ventrally oriented LPJs, 16 points (Fig. 2d), including landmarks (points 1 and 9) and semilandmarks (the remaining points), were digitized with IMAGEJ (Schneider et al. 2012). The configurations of points were then subjected to a Generalized Procrustes analysis with sliding of semilandmarks (Bookstein 1997) using the software tpsRelw (Rohlf 2007b). As pharyngeal jaws are symmetrical structures, analyses were performed only on the symmetric component of shape variation (Klingenberg et al. 2002). A multivariate regression of shape variables on body SL was carried out to account for allometric variation in shape, and residuals were used in subsequent analyses. Treatments were compared using discriminant analysis in MorphoJ (Klingenberg 2011), testing the significance of between-treatment differences in mean shape using a permutational procedure based on Procrustes distances (1000 permutations). The accuracy of classification of the discriminant function was estimated with the leaveone-out cross-validation implemented in the software.

\section{RNA extraction}

RNA was extracted from LPJs using a method modified for bone tissue, which combines Trizol (Invitrogen) with RNeasy (Qiagen) extraction, similar to (Mantila Roosa et al. 2011b). Modifications included an additional homogenization step using a FastPrep-24 (MP Biomedicals), prior to phase separation, and an on-column DNase treatment, which was conducted according to manufacturer's instructions (Qiagen). RNA purity and integrity were assessed by spectrophotometry (Eppendorf) and Bioanalyzer 2100 (Agilent) (Table S1, Supporting Information).

\section{Candidate gene $q R T-P C R$}

Sixteen candidate genes were selected for qRT-PCR analysis (Table 1). These include genes that are known to establish tooth size and patterning [pitx2, eda, shh, bmp2, bmp4, described in (Fraser et al. 2008, 2009)], genes that respond to mechanical strain in mammalian bones [bmp2 and bmp4 (Sato et al. 1999), pghs2 
Table 1 Candidate genes and their anticipated expression in response to a mechanically stimulating diet

\begin{tabular}{|c|c|}
\hline $\begin{array}{l}\text { Putative function } \\
\text { and gene name }\end{array}$ & Predicted expression \\
\hline \multicolumn{2}{|l|}{ Tooth patterning } \\
\hline pitx2 & Up in HD (Fraser et al. 2008, 2009) \\
\hline eda & Up in HD (Fraser et al. 2008, 2009) \\
\hline $\operatorname{shh}$ & Up in HD (Fraser et al. 2008, 2009) \\
\hline bmp2 & Up in HD (Fraser et al. 2008, 2009) \\
\hline bmp4 & Up in HD (Fraser et al. 2008, 2009) \\
\hline \multicolumn{2}{|c|}{ Mechanical strain response } \\
\hline Nnos & Up in HD (Rubin et al. 2003) \\
\hline$c x 43$ & Up in HD (Su et al. 1997) \\
\hline pghs2 & Up in HD (Klein Nulend et al. 1997) \\
\hline wnt5a & Up in HD (Hadjiargyrou et al. 2002) \\
\hline$\beta$ catenin & Up in HD (Robinson et al. 2006) \\
\hline bmp2 & Up in HD (Sato et al. 1999) \\
\hline bmp4 & Up in HD (Sato et al. 1999) \\
\hline \multicolumn{2}{|c|}{ Osteoblast pathway } \\
\hline runx $2 a$ & $\begin{array}{l}\text { Up in HD (Ducy et al. 1997; } \\
\text { Komori et al. 1997) }\end{array}$ \\
\hline $\operatorname{runx} 2 b$ & $\begin{array}{l}\text { Up in HD (Ducy et al. 1997; } \\
\text { Komori et al. 1997) }\end{array}$ \\
\hline $\cos x$ & Up in HD (Nakashima et al. 2002) \\
\hline$a p$ & Up in HD (Owen et al. 1990) \\
\hline bmp2 & Up in HD (Tsuji et al. 2006) \\
\hline \multicolumn{2}{|l|}{ Osteoclast pathway } \\
\hline opg & Up in HD (Udagawa et al. 2000) \\
\hline RANKL & Up in HD (Schoppet et al. 2002) \\
\hline
\end{tabular}

(Klein-Nulend et al. 1997), nos (Rubin et al. 2003), cx43 (Su et al. 1997), wnt5a (Hadjiargyrou et al. 2002) and $\beta$-catenin (Robinson et al. 2006)], representatives of the osteoblast proliferation/differentiation pathway (runx2a) $2 b$ (Ducy et al. 1997; Komori et al. 1997), osx (Nakashima et al. 2002), ap (Owen et al. 1990) and bmp2 (Tsuji et al. 2006)) and the osteoclast pathway (opg (Udagawa et al. 2000) and RANK-L (Schoppet et al. 2002)). It was hypothesized that each of these genes may be upregulated in response to the HD treatment (Table 1), thus contributing to the molariform morphology, representing a departure from the baseline condition of this species. Specifically, the upregulation of: mechanical strain response genes would occur in response to snail cracking, the upregulation of osteoblast proliferation/differentiation genes and osteoblast pathway genes together would explain the alterations in size and shape, and tooth-patterning genes would be required for the development of enlarged tooth germs.

Eight of these genes were cloned using degenerate primers (pghs2, nos, wnt5a, $\beta$-catenin runx $2 a / 2 b$, os $x$, ap, opg and RANK-L; Table S2, Supporting Information), and the remaining eight were obtained from transcriptome reads generated by our RNA-seq experiment (see below). Orthology was confirmed through construction of maximum-likelihood trees using Jalview (Waterhouse et al. 2009) and PhyML (Guindon et al. 2010) (Fig. S1, Supporting Information).

Primer pairs were designed so that the reverse primer was situated in the 3' UTR of each gene (Table S2, Supporting Information). Primer concentration was optimized so that negligible dimers were produced in the negative control ( $>10$ cycles after the positive control). RNA was verified to be free from gDNA contamination through noRT control reactions. cDNA was synthesized from $1.0 \mu \mathrm{g}$ of each RNA using Superscript III (Invitrogen), primed with oligodT and diluted 1:10 for use in qRT-PCR reactions. Reactions were run on 22 cDNA samples (12 HD and 10 SD) using a cfx96 Real Time System (Bio-Rad) with the SYBR green iQ supermix (Bio-Rad), using the following conditions: $95{ }^{\circ} \mathrm{C} 3 \mathrm{~min}$, then 40 cycles of $95{ }^{\circ} \mathrm{C} 10 \mathrm{~s}, 5560{ }^{\circ} \mathrm{C} 30 \mathrm{~s}, 72{ }^{\circ} \mathrm{C} 30 \mathrm{~s}$. Efficiency was calculated through the generation of a standard curve, based on serial dilutions of pooled cDNAs (1:5, 1:10, 1:20, 1:40, 1:80). Housekeeping genes were selected from the RNA-seq results (see below), searching for genes with the lowest between-sample variability. The housekeeping genes were tested using qBase (Hellemans et al. 2007), and two genes, actinR and twinfilin were shown to display sufficiently low variability to enable the calculation of a reliable normalization factor (NF). Relative quantitation was calculated for each sample using the algorithm described in (Simon 2003), which were scaled against NF. Comparisons of the levels of gene expression between treatments were then performed using the bootstrap version of the $t$-test implemented in SPSS (IBM Corp.).

\section{RNA-seq}

We performed RNA-seq in an effort to identify novel regulators of plasticity in the Astatoreochromis alluaudi LPJ. Ten individually barcoded cDNA libraries were synthesized (Table S1, Supporting Information) using the Illumina TruSeq RNA sample preparation kit according to manufacturer's instructions (Illumina, San Diego, CA, USA). The barcoding enabled multiplexing, eliminating potential biases created by lane-to-lane variability (Auer \& Doerge 2010). Paired-end sequencing (72 bp from each end) of clustered template cDNA was performed using an Illumina Genome Analyzer IIx (Illumina). The resulting reads were then trimmed with CLC Genomic Workbench (version 4.9; CLC bio, Aarhus, Denmark), and de novo assembled using VELVET (version 1.2.01) (Zerbino \& Birney 2008) and OASES (version 0.2.05) (Schulz et al. 2012) with Kmer lengths ranging from 29 to 49. Annotation was performed through blastx comparison to the Medaka genome, a model system that is closely related to cichlids, in the Ensembl database (Hubbard et al. 2002). We 
mapped the filtered reads to the assembled transcripts using BOWTIE (version 0.12.9) (Langmead et al. 2009) and extracted the digital expression value for each sample using EXPREss (version 1.3.0) (Roberts \& Pachter 2012). Differentially expressed (DE) genes were identified through comparisons between the LPJ samples of 5 HD (molariform) and 5 SD (papilliform) individuals (Table S1, Supporting Information), using edgeR (version 3.0.8) (Robinson et al. 2010) and DESeq (Anders \& Huber 2010), with correction of false discovery rate 0.1 . Both edgeR and DESeq (version 1.10.1) are based on a negative binomial model, but they also differ in a few steps [for example, see Dillies et al. (2012)]. Only the genes that were identified by both edgeR and DESeq (a total of 183) were included in further analyses this conservative approach has been endorsed by recent research as a means of controlling the inclusion of false positives in RNA-seq results (Yendrek et al. 2012). K-means clustering of the DE genes was performed based on a K-means calculation script (define clusters by cutting tree.pl) on the Trinity website (Grabherr et al. 2011).

To perform the functional annotation of the DE genes, we first converted the Medaka annotations to Human Ensembl gene ID (Release 70). Results were further characterized using the online functional classification tool, DAVID (version 6.7) (Huang et al. 2008). Gene functional classification and functional annotation clustering were both performed. Two separate gene lists were generated for functional annotation clustering, comprised of genes that were, on average, up- or downregulated in HD relative to SD. Reported results include clusters with significant EASE scores $(>1.0)$ and annotation terms with $P$ values above 0.1 after performing Benjamini Hochberg multiple testing correction (Benjamini \& Hochberg 1995).

\section{Results}

Diet influences size and shape of LPJ and teeth in Astatoreochromis alluaudi

After exposing Astatoreochromis alluaudi to the hard and soft diets for a period of 18 months, LPJs were dissected and linear and geometric morphometric measurements were made. The two diet treatments, which included intact and pulverized snails, resulted in marked differences in the size and shape of the LPJs and size of the teeth, (Fig. 3a c; Table S3, Supporting Information), similar to other previous publications (Hoogerhoud 1986b; Huysseune et al. 1994; Huysseune 1995; Smits 1996). Taking into account allometric and sex-related variation, all measurements except one, largest tooth size, differed significantly between diethardness treatments (Table S3, Supporting Information). The first two principal components accounted cumula-
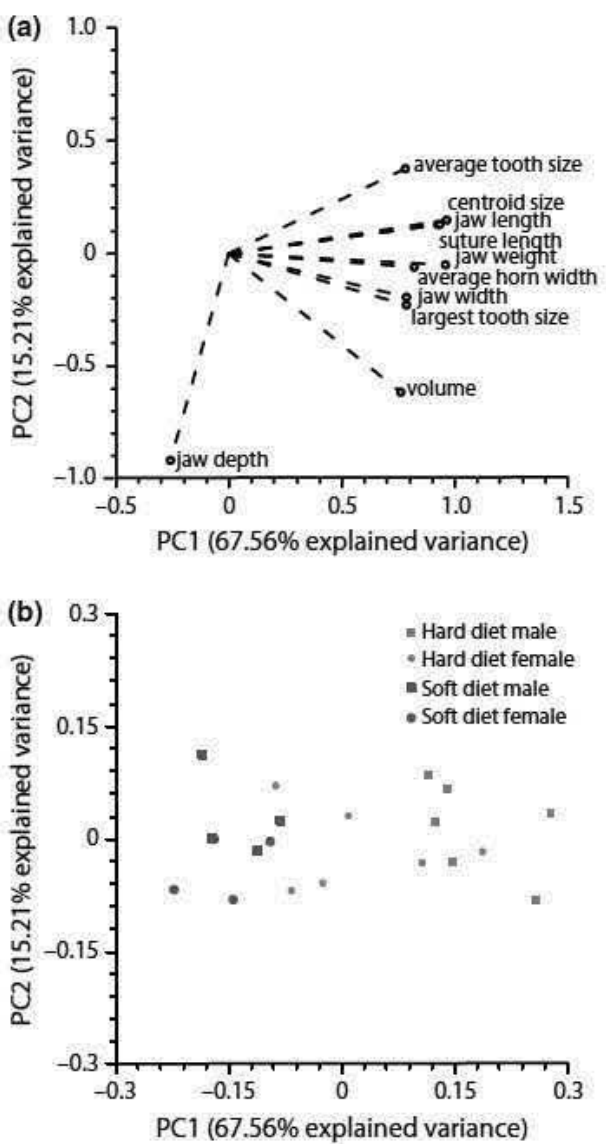

(c)

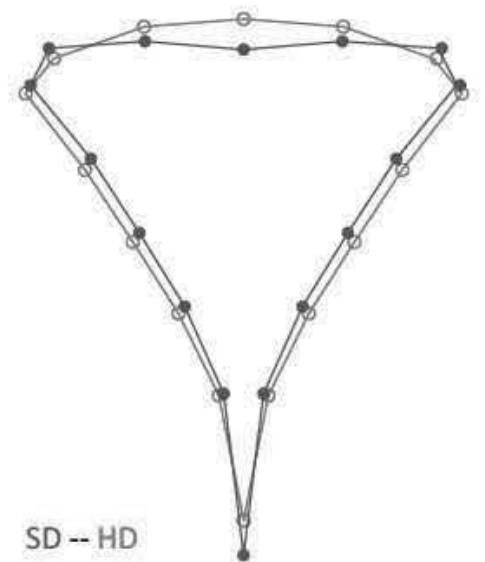

Fig. 3 Diet treatment induces plastic phenotypes in the LPJ of Astatoreochromis alluaudi. (a) Correlation of the original variables with the first two PC axes. (b) Scatterplot of the indi vidual observation scores along the first two PC axes. (c) Geo metric morphometric analysis indicates a significant difference $(P<0.001)$ in shape between diet treatments; predicted shape for the hard diet treatment in red, predicted shape for the soft diet in blue.

tively for $88.77 \%$ of variance. All included measurements except LPJ depth are highly and positively correlated with the first PC axis (Fig. 3a). The plot of 
the individual scores along the first two principal components shows a clear clustering of the two diet treatments (Fig. 3b). Geometric morphometric analyses of the LPJs indicate significant shape differences as a result of the diet treatment $(P<0.001)$ with an $87.5 \%$ cross-validated correct classification rate. Specifically, the LPJs of the HD fish display a pronounced enlargement of the medial posterior edge and a relative reduction in keel length in comparison with SD fish (Fig. 3c), a classic hallmark of molariformity, also observed in noncichlid LPJs (Fruciano et al. 2011). These are known adaptations for feeding on hard diets and did not develop in response to the soft diet treatment.

\section{Mechanically stimulating diet induces altered candidate gene expression}

Candidate gene expression was conducted using qRTPCR on the RNA extracted from the LPJs of hard diet (HD) and soft diet (SD) fish (Tables S1 and S2, Supporting Information). All genes that displayed significant differential expression were upregulated in HD jaws, confirming our hypothesis; however, contrary to our predictions, most genes did not differ in their expression between HD and SD jaws (Fig. 4a, Table S4, Supporting Information). Significant expression differences were detected for some representatives of the osteoblast proliferation and differentiation pathways (bmp2, run $x 2 b$, os $x$; Fig. 4a, Table S4, Supporting Information) (Rickard et al. 1994; Ducy et al. 1997; Nakashima et al. 2002; Nakashima \& de Crombrugghe 2003), but not others (runx $2 a, a p)$. We also detected significant differential expression of some genes stimulated by mechanical strain in bone (cx43, bmp2) (Ziambaras et al. 1998; Sato et al. 1999), but not others (pghs2, nnos, wnt5a, $\beta$-catenin; Fig. $4 \mathrm{~b}$, Table S4, Supporting Information). The difference in the expression of only one marker of tooth size and shape was found to be significantly differential (bmp2), whereas the others were not (pitx 2, eda, shh, bmp4), and neither were the osteoclast pathway markers (rank-l, opg; Fig. 4c, Table S4, Supporting Information). However, as the LPJ contains many tissue types that are each represented in the homogenized samples of the entire LPJ, we cannot rule out the possibility that these genes (or their protein products) play an important role in shaping the LPJ phenotypes that was not detected by our study.

\section{Genome-wide transcriptional response to mechanical strain in the LPJ}

A genome-wide transcriptome analysis (RNA-seq) was utilized to identify potentially novel transcriptional differences between HD and SD individuals that were not
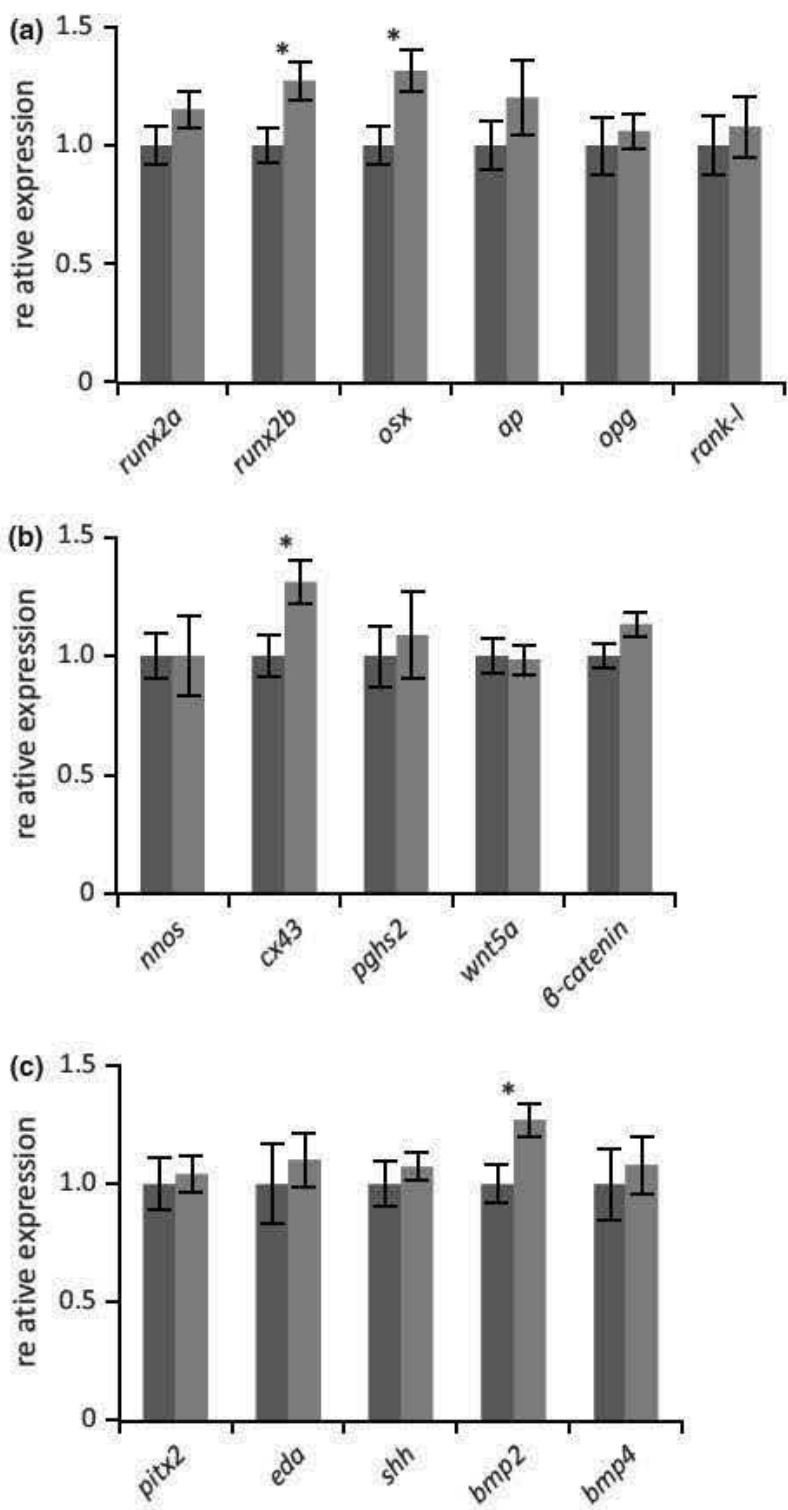

Fig. 4 Candidate gene expression analysis of LPJs from Astato reochromis alluaudi fed hard and soft diets. Candidates include markers for (a) osteoclasts and osteoblasts (b) mechanical strain response and (c) tooth number and size. Note that some of the genes in this list have pleiotropic functions, such as bmp2 and bmp4, which also respond to mechanical strain. Blue bars denote means of relative expression in LPJs of soft diet indi viduals and red bars denote relative expression in hard diet LPJs. SD mean is scaled to 1 and standard error indicated. Asterisks indicate statistical significance according to bootstrap $t$ test (for further details see Table S4, Suppoting Information).

included in the candidate gene-based qRT-PCR approach. This technique uses next-generation sequencing to generate shotgun sequences of cDNA libraries (reads), which, through de novo assembly of transcripts, enables the relative quantification of transcript abundance (Wang et al. 2009). Differential expression (DE) 
was analysed using edgeR (Robinson et al. 2010) and DESeq (Anders \& Huber 2010), yielding a total of 183 genes (Table S5, Supporting Information), which were the subjects of further analyses. A total of 16698 transcripts were detected amongst our samples. Although some transcripts were undetected for a few samples, each was identified in at least a few individuals of both HD and SD treatments. The significant DE genes did not include any of the original candidates, most likely due to their low mean HD/SD ratios maximally 1.315 (Table S4, Supporting Information), while the lowest mean HD/SD ratio shown amongst DE RNA-seq genes was 1.496 (Table S5, Supporting Information).

$\mathrm{K}$-means clustering ( $\left.\begin{array}{ll}k & 5\end{array}\right)$ identified two main blocks of genes that were either up- or downregulated in HD vs. SD individuals, in addition to three further clusters with expression that does not adhere strictly to the diet groups (Fig. 5a). Nonetheless, each of the five replicate individuals from the $\mathrm{HD}$ and SD groups clustered together, indicating that a mechanically stimulating diet induces a characteristic expression pattern in the LPJ. The three variable clusters contained between 1 and 4 transcripts, each with rather different expression profiles. Thus, we chose to focus on genes up- and downregulated in the HD and SD treatments. The HD treatment stimulated the upregulation of 137 genes, whereas only 46 displayed significantly higher expression in the SD treatment. A rich array of gene classes was induced in the HD LPJs, including muscle-related proteins, various signalling pathways, extracellular matrix and cytoskeleton-related genes (Fig. 5b; Tables S6 and S7 Supporting Information). However, upregulated genes in the SD treatment predominantly included genes most likely involved in the inflammatory response, such as cytokines and chemokines (Fig. 5b; Tables S6 and S8 Supporting Information). As the SD treatment mimics the ground state of this species, it is inferred that expression of these inflammation-related
Fig. 5 Transcriptome characterization of response to mechanical strain in the LPJ of Astatoreochromis alluaudi. (a) Heatmap of genes displaying significantly differen tial expression between HD and SD treat ments, as identified by both edgeR and DESeq. (b) Results of gene functional classification clustering generated with DAVID. Category labels represent the top classifying term for each significant gene group identified. Colour coding represents average fold change of genes in each cluster, upregulated in HD red, upregulated in SD blue.

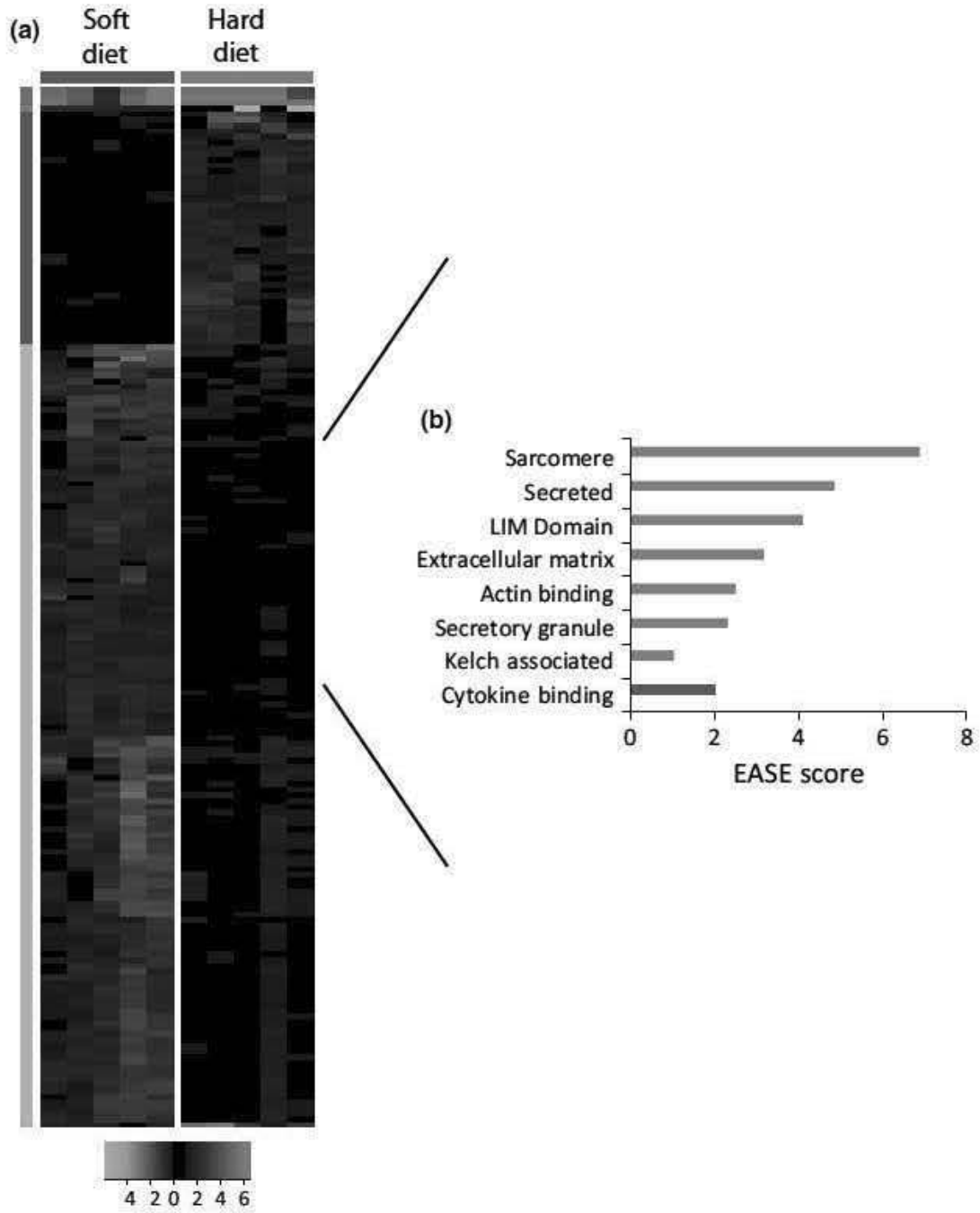


Table 2 Gene families identified by RNA seq, also altered by mechanical strain in mammalian bones

\begin{tabular}{|c|c|}
\hline Gene name and putative function & Reference \\
\hline \multicolumn{2}{|l|}{ Apoptosis } \\
\hline c1q tumour necrosis factor related protein 3 & Xing et al. (2005) \\
\hline \multicolumn{2}{|l|}{ Calcium signalling } \\
\hline Annexin a6 isoform 1 & Mantila Roosa et al. (2011b) \\
\hline Synaptotagmin 2 & Mantila Roosa et al. (2011b) \\
\hline \multicolumn{2}{|l|}{ Cell cycle } \\
\hline Lymphocyte g0 g1 switch protein 2 & Mantila Roosa et al. (2011b) \\
\hline \multicolumn{2}{|l|}{ Chemokine } \\
\hline c c chemokine receptor type 7 & $\begin{array}{l}\text { Mantila Roosa et al. (2011b) } \\
\text { Xing et al. (2005) }\end{array}$ \\
\hline c c chemokine receptor type 9 & $\begin{array}{l}\text { Mantila Roosa et al. (2011b) } \\
\text { Xing et al. (2005) }\end{array}$ \\
\hline c x c chemokine receptor type 5 & $\begin{array}{l}\text { Mantila Roosa et al. (2011b) } \\
\text { Xing et al. (2005) }\end{array}$ \\
\hline \multicolumn{2}{|l|}{ Cytokine } \\
\hline Interleukin 8 & Mantila Roosa et al. (2011b) \\
\hline Interleukin 20 receptor subunit alpha & $\begin{array}{l}\text { Mantila Roosa et al. (2011b) } \\
\text { Xing et al. (2005) }\end{array}$ \\
\hline \multicolumn{2}{|l|}{ Cytoskeleton } \\
\hline \multicolumn{2}{|l|}{ Leiomodin 2} \\
\hline pdz and lim domain protein 3 & Plakophilin 1 isoform 1 \\
\hline \multicolumn{2}{|l|}{ Sarcolemmal membrane associated protein } \\
\hline \multicolumn{2}{|l|}{ Heat shock proteins } \\
\hline Heat shock protein beta 1 & Xing et al. (2005) \\
\hline Heat shock protein beta 8 & Xing et al. (2005) \\
\hline Heat shock protein 30 & Xing et al. (2005) \\
\hline Heat shock cognate 71 kda protein & Xing et al. (2005) \\
\hline \multicolumn{2}{|l|}{ Immediate early response } \\
\hline c fos protein & Mantila Roosa et al. (2011b) \\
\hline Immediate early response 2 & Mantila Roosa et al. (2011b) \\
\hline \multicolumn{2}{|l|}{ Ion channel } \\
\hline Voltage dependent calcium channel gamma 6 subunit & Mantila Roosa et al. (2011b) \\
\hline ATP sensitive inward rectifier potassium channel 11a & Mantila Roosa et al. (2011b) \\
\hline Trimeric intracellular cation channel type a & Mantila Roosa et al. (2011b) \\
\hline \multicolumn{2}{|l|}{ Matrix } \\
\hline Collagen 6A3 & $\begin{array}{l}\text { Mantila Roosa et al. (2011b) } \\
\text { Xing et al. (2005) }\end{array}$ \\
\hline Collagen $12 \mathrm{~A} 1$ & $\begin{array}{l}\text { Mantila Roosa et al. (2011b) } \\
\text { Xing et al. (2005) }\end{array}$ \\
\hline Fibronectin type iii domain containing protein 1 & Xing et al. (2005) \\
\hline Hyaluronan and proteoglycan link protein 1 & Mantila Roosa et al. (2011b) \\
\hline Protocadherin fat 3 like & Xing et al. (2005) \\
\hline Spondin 2 precursor & Mantila Roosa et al. (2011b) \\
\hline \multicolumn{2}{|l|}{ Muscle } \\
\hline Desmin & Mantila Roosa et al. (2011b) \\
\hline Musculoskeletal embryonic nuclear protein 1 & Mantila Roosa et al. (2011b) \\
\hline Myosin binding protein $\mathrm{h}$ like & Mantila Roosa et al. (2011b) \\
\hline Tropomyosin alpha 4 chain like isoform 1 & $\begin{array}{l}\text { Mantila Roosa et al. (2011b) } \\
\text { Xing et al. (2005) }\end{array}$ \\
\hline Troponin C & $\begin{array}{l}\text { Mantila Roosa et al. (2011b) } \\
\text { Xing et al. (2005) }\end{array}$ \\
\hline Troponin I & $\begin{array}{l}\text { Mantila Roosa et al. (2011b) } \\
\text { Xing et al. (2005) }\end{array}$ \\
\hline Troponin $\mathrm{T}$ & $\begin{array}{l}\text { Mantila Roosa et al. (2011b) } \\
\text { Xing et al. (2005) }\end{array}$ \\
\hline
\end{tabular}


Table 2 Continued

\begin{tabular}{ll}
\hline Gene name and putative function & Reference \\
\hline Signal transduction & \\
$\quad$ G protein coupled receptor 126 like & Mantila Roosa et al. (2011b) \\
Other & Xing et al. (2005) \\
Four and a half lim domains protein 1 & Mantila Roosa et al. (2011b) \\
Immunoglobulin d & Mantila Roosa et al. (2011b) \\
lim domain protein 3 & Mantila Roosa et al. (2011b) \\
Lipoxygenase 3, epidermis type like & Mantila Roosa et al. (2011b) \\
Regulator of g protein signalling 2 & Xing et al. (2005) \\
Semaphorin 3c precursor & Xing et al. (2005) \\
Ubiquitin carboxyl terminal hydrolase28 & Mantila Roosa et al. (2011b) \\
\hline
\end{tabular}

genes is suppressed in $\mathrm{HD}$, rather than being induced in SD.

Notably, our analysis indicated that a substantial number of genes or related gene family members induced in A. alluaudi in response to mechanical strain are also observed in studies on mechanical strain in mammalian bones [(Mantila Roosa et al. 2011a,b; Xing et al. 2005), Table 2]. This demonstrates an astonishing degree of evolutionary and apparently functional conservation of molecular bone remodelling mechanisms between mammals and teleosts.

\section{Discussion}

There is mounting evidence that phenotypic plasticity generates adaptive phenotypic variation; however, the underlying genetic and developmental mechanisms for phenotypic plasticity remain largely unknown (WestEberhard 2003, 2005; Aubin-Horth \& Renn 2009; Jablonka \& Raz 2009; Beldade et al. 2011). Emerging techniques such as RNA-seq, when used in combination with classical split brood and common garden experiments, can shed light on the molecular basis of phenotypic plasticity in natural populations opening the door to empirically test long-standing controversial theories such as genetic assimilation. The lower pharyngeal jaw (LPJ) of Astatoreochromis alluaudi represents a classical model for phenotypic plasticity, with research dating back almost 50 years (Greenwood 1965; Hoogerhoud 1986a,b; Huysseune et al. 1994; Huysseune 1995; Smits et al. 1996a,b). Our study represents the first molecular investigation of skeletal plasticity in a cichlid fish, determining the transcriptional basis of phenotypic plasticity in the LPJ, a key evolutionary innovation of cichlids.

Amongst the 187 genes that displayed significant differential expression in response to hard diet (including 183 from RNA-seq and 4 from qRT-PCR) are many genes that respond to mechanical strain in the bones of mammals. Thus, our results support the hypothesis that the mechanical strain received from cracking hardshelled snails shapes the molariform morphology (Table 2). Mechanical strain in the bones of mammals induces a suite of biochemical pathways, via localized alterations to fluid flow and subsequent deformation of cellular membranes, which subsequently induce a dramatic transcriptional response (Thompson et al. 2012). Briefly after exposure to even a single loading, mechanical strain induces the expression of immediate early response genes such as $c$-fos and ier2, also detected by RNA-seq in our study (Ott et al. 2009; Mantila Roosa et al. 2011b). Relevant candidate genes that were upregulated in HD LPJs include the gap junction gene $c \times 43$, which is important in coordinating the cellular response to mechanical strain in mammalian bones (Taylor et al. 2007). Additionally, regulators of osteoblast differentiation and proliferation such as bmp2 (Tsuji et al. 2006) runx2 (Ducy et al. 1997) and periostin (detected by RNAseq) (Nakazawa et al. 2004) are also induced by strain and fractures in mammals.

The functional classes of genes upregulated in HD LPJs provide a potential link between mechanical strain sensing to increased bone density, which was demonstrated for molariform A. alluaudi by previous morphological analyses (Huysseune et al. 1994). In addition to the increased expression of markers for osteoblast proliferation and differentiation (see above), we observed the over-representation of the Gene Ontology terms: extracellular matrix (ECM), intracellular calcium flux, cytoskeleton and muscle (Table 2). Mechanical strain deforms cellular membranes, inducing a characteristic signalling cascade involving calcium influx, alterations to cytoskeletal dynamics and induction of various small GTPases (Chiquet et al. 2009). This secondarily alters the expression of ECM proteins, which influence the structural properties of the ECM to resist the mechanical strain. Collagen VI and collagen XII, amongst the 
ECM genes induced in HD fish, both play critical roles in bone development and remodelling through establishing appropriate bone density and matrix organization, respectively (Izu et al. 2011; Christensen et al. 2012). Moreover, the altered expression of various ECM and cytoskeletal proteins in HD fish may influence differentiation of mesenchymal stem cells, as matrix stiffness and cell shape have a profound influence on their differentiation (McBeath et al. 2004; Engler et al. 2006). Interestingly, HD fish overexpressed mef2C, which has been identified as a QTL for bone density in humans (Rivadeneira et al. 2009). Muscle-related genes were also strongly induced in HD fish, an observation, which is consistent with mammalian transcriptome analyses (Mantila Roosa et al. 2011b), perhaps reflecting the extensive cross-talk between pathways expressed in bone and muscle cells (Jähn et al. 2011). Note, care was taken to dissect muscles away from our LPJ samples, increasing the likelihood that this observation reflects altered expression in bone rather than muscle cells.

Several of the identified genes may have pleiotropic functions in generating the molariform phenotype as they are known to function in both bone and tooth development. The teeth of teleosts are replaced continually throughout their lifetimes (estimated to be once per month in A. alluaudi (Huysseune 1995)), and it has been shown that runx2 and bmp2 play a role in cichlid tooth replacement (Fraser et al. 2013), representing a redeployment of embryonic tooth developmental pathways (Fraser et al. 2009). cx43 may also play a role in tooth replacement as it is also involved in embryonic tooth development (About et al. 2002). Also the eruption of teeth from adult jaws requires localized bone resorption by osteoclasts, which is orchestrated by c-fos (Wang et al. 1992). Moreover, $c x 43$ and $c$-fos are upregulated in response to tooth injury (Mitsiadis \& Rahiotis 2004), which may plausibly occur in the HD fish as a result of chewing hard-shelled snails. Although further spatial gene expression analyses are required to tease apart the precise function of these genes, this observation opens up the exciting possibility that a pleiotropic network of genes functions in concert to pattern both bones and teeth, seemingly separate, but surely functionally linked, aspects of the overall molariform phenotype.

In HD fish, we also observed striking downregulation of inflammatory response genes including chemokines, cytokines and MHC components, suggesting that the hard diet had an anti-inflammatory effect, which may also be linked to increased bone density. Localized inflammation is linked to increased bone resorption in rheumatoid arthritis (Goldring 2003), via activation of osteoclasts. As osteoclasts are derived from the same hematopoietic stem cell lineage as macrophages and are themselves induced by the cytokine RANK-L (Boyle et al.
2003), there is an inherent link between inflammation and bone turnover. cxcr5, one of the chemokines identified by our study, is known to function in bone remodelling through altering differentiation of hematopoietic stem cells (Manolagas \& Jilka 1995; Calvi et al. 2003; Tonnarelli et al. 2009). As pharmacological suppression of the inflammatory response is linked to increased bone density (Morton et al. 1998), and chronic exercise is linked to both increased bone density and reduced inflammation (Bruunsgaard 2005), we predict that through suppressing background levels of inflammation, HD fish achieve enhanced bone deposition, potentially though reducing the activity of osteoclasts. Further histological analyses are required to determine whether HD fish do display subphysiological levels of inflammatory cells, and whether this is concomitant with a reduced abundance of osteoclasts. Future research should also determine whether the reduced expression of inflammatory factors is localized to the LPJ, or whether it reflects immunosuppression of HD individuals, presenting a potential cost of plasticity, which may be extremely relevant amongst natural populations.

As they link strain sensing to altered cellular recruitment, the genes identified by this study provide a toolkit for determining the degree to which phenotypic plasticity shapes LPJ morphology in natural populations of A. alluaudi, and whether plasticity is playing a role in their evolution. Ecological conditions that remain stable between generations would be expected to favour the fixation of either molariform or papilliform jaw morphologies, with this trait ultimately losing its environmental sensitivity (genetic assimilation) (Waddington 1953; Crispo 2007). Indeed, A. alluaudi from Lake Saka display molariform LPJs even though hard-shelled snails only comprise a small proportion of their diet (Cosandey-Godin et al. 2008). Moreover, populations that inhabit hypoxic environments display papilliform jaws, which accommodate increased gill size, in spite of the potential to eat snails in these habitats (Binning \& Chapman 2010; Binning et al. 2010). Fixation of this plastic trait in some populations may be achieved through mutations in cisregulatory regions of plasticity-related genes that constrain their environmental responsiveness. As many of the genes included in our study are known to be mechanically responsive, their expression is likely to be mediated by shear stress responsive elements (SSREs), cis-regulatory elements of mechanically responsive genes (Nomura \& Takano-Yamamoto 2000). Alterations to the number or position of these elements might alter the degree of response to mechanical strain of these genes. Determining whether such regulatory evolution has occurred in natural populations or between closely related species of cichlids that can differ markedly in their pharyngeal jaw morphologies will be the subject of our future work. 
In conclusion, we have identified numerous transcriptional changes that contribute to phenotypic plasticity in the LPJs of $A$. alluaudi. These genes include various mechano-responsive genes identified in the bones and teeth of mammals, which will inform future studies of the cellular and developmental basis of plasticity in the LPJs. Empirical assessment of the importance of plasticity in establishing phenotypes of wild populations, and its potential importance in generating divergent PJA morphologies in distantly related cichlid species can be achieved in the future through examining the expression of genes identified by our study in a phylogenetic context. One might speculate, and we plan to test, that parallel evolution of molariform morphologies of the PJAs of different cichlid radiations is caused by the induction of similar expression patterns, which might have become fixed through the process of genetic assimilation.

\section{Acknowledgements}

We dedicate this manuscript to the memory of Frans Witte, a pioneer in cichlid biology who has recently passed away. Funding was provided by a grant from the Deutsche Fors chungsgemeinschaft to $\mathrm{HG}$, the Zukunftskolleg at the Univer sity of Konstanz to HG, the DAAD to CF and supported by the University of Konstanz to AM. We wish to thank Patrick Niemantsverdriet and Frans Witte from the University of Lei den for generously providing their strain of A. alluaudi and Eckhard Witten and Ralf Schneider for useful comments on this manuscript. Madoka Krick and Maria Louise Spreitzer are thanked for their assistance with the morphometric analysis.

\section{References}

About I, Proust JP, Raffo S, Mitsiadis TA, Franquin JC (2002) In vivo and in vitro expression of connexin 43 in human teeth. Connective Tissue Research, 43, 232237.

Anders S, Huber W (2010) Differential expression analysis for sequence count data. Genome Biology, 11, R106.

Aubin Horth N, Renn SCP (2009) Genomic reaction norms: using integrative biology to understand molecular mecha nisms of phenotypic plasticity. Molecular Ecology, 18, 3763 3780 .

Aubin Horth N, Desjardins JK, Martei YM, Balshine S, Hof mann HA (2007) Masculinized dominant females in a coop eratively breeding species. Molecular Ecology, 16, 13491358.

Auer PL, Doerge RW (2010) Statistical design and analysis of RNA sequencing data. Genetics, 185, 405416.

Beldade P, Mateus ARA, Keller RA (2011) Evolution and molecular mechanisms of adaptive developmental plasticity. Molecular Ecology, 20, 13471363.

Benjamini Y, Hochberg Y (1995) Controlling the false discovery rate: a practical and powerful approach to multiple testing. Journal of the Royal Statistical Society. Series B (Methodological), 57, 289300.

Binning SA, Chapman LJ (2010) Is intraspecific variation in diet and morphology related to environmental gradients? Explor ing Liem's paradox in a cichlid fish. Integrative Zoology, 5, 241255.

Binning SA, Chapman LJ, Dumont J (2010) Feeding and breath ing: trait correlations in an African cichlid fish. Journal of Zoology, 282, 140149.

Bonewald LF (2011) The amazing osteocyte. Journal of Bone and Mineral Research, 26, 229238.

Bookstein FL (1997) Landmark methods for forms without landmarks: localizing group differences in outline shape. Medical Image Analysis, 1, 225243.

Bosch TCG, McFall Ngai MJ (2011) Metaorganisms as the new frontier. Zoology, 114, 185190.

Boyle W, Simonet W, Lacey D (2003) Osteoclast differentiation and activation. Nature, 423, 337.

Bruunsgaard H (2005) Physical activity and modulation of sys temic low level inflammation. Journal of leukocyte biology, 78, 819835.

Burmeister SS, Jarvis ED, Fernald RD (2005) Rapid behavioral and genomic responses to social opportunity. Plos Biology, 3, 19962004.

Calvi LM, Adams GB, Weibrecht KW et al. (2003) Osteoblastic cells regulate the haematopoietic stem cell niche. Nature, 425, 841846.

Chamay A, Tschantz P (1972) Mechanical influences in bone remodeling. Experimental research on Wolff's law. Journal of biomechanics, 5, 173180.

Chiquet M, Gelman L, Lutz R, Maier S (2009) From mechano transduction to extracellular matrix gene expression in fibro blasts. Biochimica et Biophysica Acta, 1793, 911920.

Christensen SE, Coles JM, Zelenski NA et al. (2012) Altered Trabecular Bone Structure and Delayed Cartilage Degenera tion in the Knees of Collagen VI Null Mice. PLoS ONE, 7, e33397.

Cosandey Godin A, Binning SA, Chapman LJ (2008) Special ized morphology for a non specialized diet: Liem's paradox in an African cichlid fish. McGill Science Undergraduate Research Journal, 3, 1923.

Crispo E (2007) The Baldwin effect and genetic assimilation revisiting two mechanisms of evolutionary change mediated by phenotypic plasticity. Evolution, 61, 24692479.

Day T, McPhail JD (1996) The effect of behavioural and mor phological plasticity on foraging efficiency in the threespine stickleback (Gasterosteus sp.). Oecologia, 108, 380388.

Day T, Pritchard J, Schluter D (1994) A comparison of 2 stickle backs. Evolution, 48, 17231734.

Dillies MA, Rau A, Aubert J et al. (2012) A comprehensive evaluation of normalization methods for Illumina high throughput RNA sequencing data analysis. Briefings in Bioin formatics. doi: 10.1093/bib/bbs046 [epub ahead of print]

Ducy P, Zhang R, Geoffroy V, Ridall AL, Karsenty G (1997) Osf2/Cbfa1: a transcriptional activator of osteoblast differen tiation. Cell, 89, 747754.

Elmer KR, Reggio C, Wirth T et al. (2009) Pleistocene desicca tion in East Africa bottlenecked but did not extirpate the adaptive radiation of Lake Victoria haplochromine cichlid fishes. Proceedings of the National Academy of Sciences of the United States of America, 106, 1340413409.

Engler AJ, Sen S, Sweeney HL, Discher DE (2006) Matrix elastic ity directs stem cell lineage specification. Cell, 126, 677689.

Fraser GJ, Bloomquist RF, Streelman JT (2008) A periodic pat tern generator for dental diversity. Bmc Biology, 6, 32. 
Fraser GJ, Hulsey CD, Bloomquist RF et al. (2009) An ancient gene network is co opted for teeth on old and new jaws. Plos Biology, 7, 233247.

Fraser GJ, Bloomquist RF, Streelman JT (2013) Common devel opmental pathways link tooth shape to regeneration. Devel opmental biology, 377, 399414.

Fruciano C, Tigano C, Ferrito V (2011) Traditional and geomet ric morphometrics detect morphological variation of lower pharyngeal jaw in Coris julis (Teleostei, Labridae). Italian Journal of Zoology, 78, 320327.

Gilbert SF (2001) Ecological developmental biology: develop mental biology meets the real world. Developmental biology, 233, 112.

Gilbert SF (2012) Ecological developmental biology: environ mental signals for normal animal development. Evolution $\mathcal{E}$ Development, 14, 2028.

Goldring S (2003) Inflammatory mediators as essential elements in bone remodeling. Calcified Tissue International, 73, 97100 .

Gomez Mestre I, Buchholz DR (2006) Developmental plasticity mirrors differences among taxa in spadefoot toads linking plasticity and diversity. Proceedings of the National Academy of Sciences of the United States of America, 103, 1902119026.

Grabherr MG, Haas BJ, Yassour M et al. (2011) Full length tran scriptome assembly from RNA Seq data without a reference genome. Nature Biotechnology, 29, 644652.

Greenwood P (1959) The monotypic genera of cichlid fishes in Lake Victoria, Part II. Bulletin of the Natural History Museum. Zoology series, 7, 163177.

Greenwood PH (1965) Environmental effects on the pharyngeal mill of a cichlid fish, Astatoreochromis alluaudi, and their taxo nomic implications. Journal of the proceedings of the Linnean Society. Zoology, 176, 110.

Guindon S, Dufayard JF, Lefort V et al. (2010) New algorithms and methods to estimate maximum likelihood phylogenies: assessing the performance of PhyML 3.0. Systematic Biology, 59, 307321 .

Hadjiargyrou M, Lombardo F, Zhao SC et al. (2002) Transcrip tional profiling of bone regeneration Insight into the molec ular complexity of wound repair. Journal of Biological Chemistry, 277, 3017730182.

Hellemans J, Mortier G, De Paepe A, Speleman F, Vandesomp ele J (2007) qBase relative quantification framework and soft ware for management and automated analysis of real time quantitative PCR data. Genome Biology, 8, R19.

Hoogerhoud R (1986a) Taxonomic and ecological aspects of morphological plasticity in molluscivorous haplochromines (Pisces, Cichlidae). Annales de la Musée royale Afrique centrale Tervuren, sciences zoologique, 251, 131134.

Hoogerhoud RJC (1986b) The adverse effects of shell ingestion for molluscivorous cichlids, a constructional morphological approach. Netherlands Journal of Zoology, 37, 277300.

Huang DW, Sherman BT, Lempicki RA (2008) Systematic and integrative analysis of large gene lists using DAVID bioinfor matics resources. Nature Protocols, 4, 4457.

Hubbard T, Barker D, Birney E et al. (2002) The Ensembl gen ome database project. Nucleic acids research, 30, 3841.

Huffman LS, Mitchell MM, O'Connell LA, Hofmann HA (2012) Rising StARs: behavioral, hormonal, and molecular responses to social challenge and opportunity. Hormones and Behavior, 61, 631641
Huysseune A (1995) Phenotypic plasticity in the lower pharyn geal jaw dentition of Astatoreochromis alluaudi (Teleostei, Cic hlidae). Archives of Oral Biology, 40, 10051014.

Huysseune A, Sire JY, Meunier FJ (1994) Comparative study of lower pharyngeal jaw structure in 2 phenotypes of Astatore ochromis alluaudi (Teleostei, Cichlidae). Journal of Morphology, 221, 2543.

Izu Y, Sun M, Zwolanek D et al. (2011) Type XII collagen regu lates osteoblast polarity and communication during bone for mation. The Journal of cell biology, 193, 11151130.

Jablonka E, Raz G (2009) Transgenerational epigenetic inheri tance: prevalence, mechanisms, and implications for the study of heredity and evolution. Quarterly Review of Biology, 84, 131176.

Jahn K, Lara Castillo N, Brotto L et al. (2011) Skeletal muscle secreted factors prevent glucocorticoid induced osteocyte apoptosis through activation of B Catenin. European cells $\mathcal{E}$ materials, 24, 197.

Kishe Machumu M, Witte F, Wanink JH (2008) Dietary shift in benthivorous cichlids after the ecological changes in Lake Victoria. Animal Biology, 58, 401417.

Klein Nulend J, Burger EH, Semeins CM, Raisz LG, Pilbeam CC (1997) Pulsating fluid flow stimulates prostaglandin release and inducible prostaglandin $\mathrm{G} / \mathrm{H}$ synthase mRNA expression in primary mouse bone cells. Journal of Bone and Mineral Research, 12, 4551.

Klein Nulend J, Bacabac R, Mullender M (2005) Mechanobiolo gy of bone tissue. Pathologie biologie, 53, 576580.

Klingenberg CP (2011) MorphoJ: an integrated software pack age for geometric morphometrics. Molecular Ecology Resources, 11, 353357.

Klingenberg CP, Barluenga M, Meyer A (2002) Shape analysis of symmetric structures: quantifying variation among indi viduals and asymmetry. Evolution, 56, 19091920.

Kolbe JJ, Losos JB (2005) Hind limb length plasticity in Anolis carolinensis. Journal of Herpetology, 39, 674678.

Komori T, Yagi H, Nomura S et al. (1997) Targeted disruption of $C b f a 1$ results in a complete lack of bone formation owing to maturational arrest of osteoblasts. Cell, 89, 755764.

Langmead B, Trapnell C, Pop M, Salzberg SL (2009) Ultrafast and memory efficient alignment of short DNA sequences to the human genome. Genome Biology, 10, R25.

Lemaire V, Tobin FL, Greller LD, Cho CR, Suva LJ (2004) Mod eling the interactions between osteoblast and osteoclast activ ities in bone remodeling. Journal of Theoretical Biology, 229, 293309.

Liedert A, Kaspar D, Blakytny R, Claes L, Ignatius A (2006) Signal transduction pathways involved in mechanotransduc tion in bone cells. Biochemical and Biophysical Research Commu nications, 349, 15.

Liem KF (1973) Evolutionary strategies and morphological innovations cichlid pharyngeal jaws. Systematic Zoology, 22, 425441.

Losos JB, Creer DA, Glossip D et al. (2000) Evolutionary impli cations of phenotypic plasticity in the hindlimb of the lizard Anolis sagrei. Evolution, 54, 301305.

Mabuchi K, Miya M, Azuma Y, Nishida M (2007) Independent evolution of the specialized pharyngeal jaw apparatus in cichlid and labrid fishes. Bmc Evolutionary Biology, 7, 10.

Manolagas SC, Jilka RL (1995) Mechanisms of Disease Bone Marrow, Cytokines, and Bone Remodeling Emerging 
Insights into the Pathophysiology of Osteoporosis. New Eng land Journal of Medicine, 332, 305311.

Mantila Roosa SM, Liu Y, Turner CH (2011a) Alternative splic ing in bone following mechanical loading. Bone, 48, 543551.

Mantila Roosa SM, Liu YL, Turner CH (2011b) Gene expression patterns in bone following mechanical loading. Journal of Bone and Mineral Research, 26, 100112.

McBeath R, Pirone DM, Nelson CM, Bhadriraju K, Chen CS (2004) Cell shape, cytoskeletal tension, and RhoA regulate stem cell lineage commitment. Developmental cell, 6, 483495.

Meyer A (1987) Phenotypic plasticity and heterochrony in Cic hlasoma managuense (Pisces, Cichlidae) and their implications for speciation in cichlid fishes. Evolution, 41, 13571369.

Meyer A (1989) Cost of morphological specialization: feeding performance of the two morphs in the trophically polymorphic cichlid fish, Cichlasoma citrinellum. Oecologia, 80, 431436.

Meyer A (1993) Trophic Polymorphisms in Cichlid Fish: do they Represent Intermediate Steps during Sympatric Specia tion and Explain their Rapid Adaptive Radiation? In: Trends in Ichthyology. (eds Schroder J H, Bauer J, Schartl M), pp. 257 266. GSF Bericht 7/92, Blackwell Scientific Publications, Oxford.

Meyer A, Kocher TD, Basasibwaki P, Wilson AC (1990) Mono phyletic origin of Lake Victoria cichlid fishes suggested by mitochondrial DNA sequences. Nature, 347, 550553.

Mitsiadis TA, Rahiotis C (2004) Parallels between tooth devel opment and repair: conserved molecular mechanisms follow ing carious and dental injury. Journal of Dental Research, 83, 896902.

Morton D, EL B C, Schneider D (1998) Nonsteroidal Anti Inflammatory Drugs and Bone Mineral Density in Older Women: The Rancho Bernardo Study. Journal of Bone and Mineral Research, 13, 19241931.

Moss ML (1962) Studies of acellular bone of teleost fish. II. Response to fracture under normal and acalcemic conditions. Acta Anatomica, 48, 4660 .

Muschick M, Barluenga M, Salzburger W, Meyer A (2011) Adaptive phenotypic plasticity in the Midas cichlid fish pha ryngeal jaw and its relevance in adaptive radiation. Bmc Evo lutionary Biology, 11, 116.

Nakashima K, de Crombrugghe B (2003) Transcriptional mech anisms in osteoblast differentiation and bone formation. Trends in Genetics, 19, 458466.

Nakashima K, Zhou X, Kunkel G et al. (2002) The novel zinc finger containing transcription factor Osterix is required for osteoblast differentiation and bone formation. Cell, 108, 1729.

Nakazawa T, Nakajima A, Seki N et al. (2004) Gene expression of periostin in the early stage of fracture healing detected by cDNA microarray analysis. Journal of orthopaedic research, 22, 520525.

Nomura S, Takano Yamamoto T (2000) Molecular events caused by mechanical stress in bone. Matrix Biology, 19, 91 96.

Ott CE, Bauer S, Manke T et al. (2009) Promiscuous and depo larization induced immediate early response genes are induced by mechanical strain of osteoblasts. Journal of Bone and Mineral Research, 24, 12471262.

Owen TA, Aronow M, Shalhoub V et al. (1990) Progressive development of the rat osteoblast phenotype invitro reciprocal relationships in expression of genes associated with osteoblast proliferation and differentiation during for mation of the bone extracellular matrix. Journal of Cellular Physiology, 143, 420430.

Pigliucci M (2007) Do we need an extended evolutionary syn thesis? Evolution, 61, 27432749.

Renn SCP, Aubin Horth N, Hofmann HA (2008) Fish and chips: functional genomics of social plasticity in an African cichlid fish. Journal of experimental biology, 211, 30413056.

Rickard DJ, Sullivan TA, Shenker BJ, Leboy PS, Kazhdan I (1994) Induction of rapid osteoblast differentiation in rat bone marrow stromal cell cultures by dexamethasone and BMP 2. Developmental biology, 161, 218228.

Rivadeneira F, Styrkársdottir U, Estrada K et al. (2009) Twenty bone mineral density loci identified by large scale meta anal ysis of genome wide association studies. Nature genetics, $\mathbf{4 1}$ 11991206.

Roberts A, Pachter L (2012) Streaming fragment assignment for real time analysis of sequencing experiments. Nature Meth ods, 10, 7173 .

Robinson JA, Chatterjee Kishore M, Yaworsky PJ et al. (2006) Wnt/beta catenin signaling is a normal physiological response to mechanical loading in bone. Journal of Biological Chemistry, 281, 3172031728

Robinson MD, McCarthy DJ, Smyth GK (2010) edgeR: a Bio conductor package for differential expression analysis of dig ital gene expression data. Bioinformatics, 26, 139140.

Rohlf FJ (2007a) NTSYSpc: Numerical taxonomy system. Version 2.20 n. Exeter Publishing, Setauket, NY.

Rohlf FJ (2007b) Tpsrelw, relative warps analysis, Version 1.45 . Department of Ecology and Evolution, State University of New York at Stony Brook, Stony Brook, NY.

Rubin J, Murphy TC, Zhu LP et al. (2003) Mechanical strain differentially regulates endothelial nitric oxide synthase and receptor activator of nuclear kappa $B$ ligand expression via ERK1/2 MAPK. Journal of Biological Chemistry, 278, 34018 34025 .

Salzburger W, Mack T, Verheyen E, Meyer A (2005) Out of Tanganyika: genesis, explosive speciation, key innovations and phylogeography of the haplochromine cichlid fishes. Bmc Evolutionary Biology, 5, 17.

Sato M, Ochi T, Nakase T et al. (1999) Mechanical tension stress induces expression of bone morphogenetic protein (BMP) 2 and BMP 4, but not BMP 6, BMP 7, and GDF 5 mRNA, during distraction osteogenesis. Journal of Bone and Mineral Research, 14, 10841095.

Schmalhausen II (1949) Factors of evolution: the theory of sta bilizing selection.

Schneider CA, Rasband WS, Eliceiri KW (2012) NIH Image to ImageJ: 25 years of image analysis. Nature Methods, 9, 671675.

Schoppet M, Preissner KT, Hofbauer LC (2002) RANK ligand and osteoprotegerin Paracrine regulators of bone metabo lism and vascular function. Arteriosclerosis Thrombosis and Vascular Biology, 22, 549553.

Schulz MH, Zerbino DR, Vingron M, Birney E (2012) Oases: robust de novo RNA seq assembly across the dynamic range of expression levels. Bioinformatics, 28, 10861092.

Schwander T, Leimar O (2011) Genes as leaders and followers in evolution. Trends in Ecology \& Evolution, 26, 143151.

Simon P (2003) Q Gene: processing quantitative real time RT PCR data. Bioinformatics, 19, 14391440. 
Slootweg R, Malek EA, Mccullough FS (1994) The Biological Control of Snail Intermediate Hosts of Schistosomiasis by Fish. Reviews in Fish Biology and Fisheries, 4, 6790.

Smits JD (1996) Trophic Flexibility through Spatial Reallocation of Anatomical Structures in the Cichlid Fish Astatoreochromis allu audi. $\mathrm{PhD}$ Thesis, University of Leiden, Leiden.

Smits JD, Witte F, Povel GDE (1996a) Differences between inter and intraspecific architectonic adaptations to pharyn geal mollusc crushing in cichlid fishes. Biological Journal of the Linnean Society, 59, 367387.

Smits JD, Witte F, VanVeen FG (1996b) Functional changes in the anatomy of the pharyngeal jaw apparatus of Astatoreochromis alluaudi (Pisces, Cichlidae), and their effects on adjacent struc tures. Biological Journal of the Linnean Society, 59, 389409.

Stauffer JR, Gray EV (2004) Phenotypic plasticity: its role in trophic radiation and explosive speciation in cichlids (Teleo stei: Cichlidae). Animal Biology, 54, 137158.

Stiassny MLJ, Jensen JS (1987) Labroid interrelationships revis ited: morphological complexity, key innovations and the study of comparative diversity. Bulletin of the Museum of Comparative Zoology, 151, 269319.

Su M, Borke JL, Donahue HJ et al. (1997) Expression of connex in 43 in rat mandibular bone and periodontal ligament (PDL) cells during experimental tooth movement. Journal of Dental Research, 76, 13571366.

Taylor AF, Saunders MM, Shingle DL et al. (2007) Mechanically stimulated osteocytes regulate osteoblastic activity via gap junctions. American Journal of Physiology Cell Physiology, 292, C545 C552.

Thompson WR, Rubin CT, Rubin J (2012) Mechanical regula tion of signaling pathways in bone. Gene, 503, 179193.

Tonnarelli B, Manferdini C, Piacentini A et al. (2009) Surface ,Aêdependent modulation of proliferation, bone matrix mol ecules, and inflammatory factors in human osteoblasts. Jour nal of Biomedical Materials Research Part A, 89, 687696.

Tsuji K, Bandyopadhyay A, Harfe BD et al. (2006) BMP2 activity, although dispensable for bone formation, is required for the initiation of fracture healing. Nature genetics, 38, 14241429.

Udagawa N, Takahashi N, Yasuda H et al. (2000) Osteoproteg erin produced by osteoblasts is an important regulator in osteoclast development and function. Endocrinology, 141, 34783484

Waddington CH (1953) Genetic assimilation of an acquired character. Evolution, 7, 118126.

Wang ZQ, Ovitt C, Grigoriadis AE et al. (1992) Bone and hema topoietic defects in mice lacking c fos. Nature, 360, 741745.

Wang Z, Gerstein M, Snyder M (2009) RNA Seq: a revolution ary tool for transcriptomics. Nature Reviews Genetics, 10, 57 63.

Waterhouse AM, Procter JB, Martin DMA, Clamp M, Barton GJ (2009) Jalview Version 2 a multiple sequence alignment editor and analysis workbench. Bioinformatics, 25, 11891191.

West Eberhard MJ (2003) Developmental Plasticity and Evolution. Oxford University Press, New York, NY.

West Eberhard MJ (2005) Developmental plasticity and the ori gin of species differences. Proceedings of the National Academy of Sciences of the United States of America, 102, 65436549.

Wimberger PH (1994) Trophic Polymorphisms, Plasticity and Speciation in Vertebrates. University of South Carolina Press, Coloumbia, SC.
Witte F (1981) Initial results of the ecological survey of the haplochromine cichlid fishes from the Mwanza Gulf of Lake Victoria (Tanzania) breeding patterns, trophic and species distribution with recommendations for commer cial trawl fishery. Netherlands Journal of Zoology, 31, 175 202.

Witten PE, Huysseune A (2009) A comparative view on mecha nisms and functions of skeletal remodelling in teleost fish, with special emphasis on osteoclasts and their function. Bio logical Reviews, 84, 315346.

Wund MA, Baker JA, Clancy B, Golub JL, Fosterk SA (2008) A test of the "Flexible stem" model of evolution: ancestral plas ticity, genetic accommodation, and morphological divergence in the threespine stickleback radiation. American Naturalist, 172, 449462.

Xing W, Baylink D, Kesavan C et al. (2005) Global gene expres sion analysis in the bones reveals involvement of several novel genes and pathways in mediating an anabolic response of mechanical loading in mice. Journal of Cellular Biochemistry, 96, 10491060.

Yendrek CR, Ainsworth EA, Thimmapuram J (2012) The bench scientist's guide to statistical analysis of RNA Seq data. BMC Research Notes, 5, 506.

Zerbino DR, Birney E (2008) Velvet: algorithms for de novo short read assembly using de Bruijn graphs. Genome Research, 18,821829 .

Ziambaras K, Lecanda F, Steinberg TH, Civitelli R (1998) Cyclic stretch enhances gap junctional communication between osteoblastic cells. Journal of Bone and Mineral Research, 13, 218228.

A.M. and H.G. conceived and designed the experiments; H.G. and X.F. performed the split-brood experiment and qRT-PCR; P.F. performed RNA-seq; H.G., S.F., P.F. and C.F. analyzed the data. H.G. wrote the manuscript, with all authors contributing.

\section{Supporting information}

Additional supporting information may be found in the online ver sion of this article.

Table S1 Specimens used in this study.

Table S2 Primers used in this study. 
Table S3 ANCOVA of log LPJ size metrics against diet, sex and SL.

Table S4 Bootstrap $t$ tests of qRT PCR analysis in the LPJs of $\mathrm{HD}$ and SD individuals.

Table S5 Genes with significantly differential expression between HD and SD.

Table S6 Significant gene functional classification clusters.
Table S7 Functional annotation clustering for genes upregulated in HD.

Table S8 Functional annotation clustering for genes downregu lated in HD.

Fig. S1 Candidate genes used in this study. 